\title{
Os sentidos do Papanicolaou para um grupo de mulheres que realizou a prevenção do câncer cervical
}

\author{
Significance of the Pap smear test for a group of women \\ undergoing cervical cancer prevention
}

\author{
Edemilson Antunes de Campos ${ }^{1}$
}

\begin{abstract}
Resumo
Introdução: O câncer cervical é uma neoplasia maligna que atinge milhares de mulheres, e a estratégia de prevenção considerada mais efetiva para essa doença é por meio Papanicolaou. Objetivo: o objetivo deste artigo é compreender os sentidos do Papanicolaou para um grupo de mulheres que realizou a prevenção do câncer cervical. Método: Trata-se de uma pesquisa qualitativa, com abordagem etnográfica, com nove mulheres em idade reprodutiva, moradoras do Jardim Keralux, localizado na zona leste da cidade de São Paulo. A escolha desse local deveu-se ao fato de que é um bairro cuja população é considerada vulnerável para o acesso das redes de prevenção ao câncer de colo do útero. Foi realizada uma análise de conteúdo das entrevistas. Resultados: O Papanicolaou é carregado de significados que deslizam entre os planos físico e moral da vida desse grupo de mulheres. O Papanicolaou torna visível não só a doença no interior do corpo feminino, reforçando a crença nas possibilidades de tratamento e cura, mas também o leque de relações nas quais as mulheres estão envolvidas, particularmente as de gênero do contexto sociocultural. Conclusão: O Papanicolaou passa a fazer parte do cuidado à saúde desse grupo de mulheres, reforçando suas crenças na prevenção do câncer cervical.
\end{abstract}

Palavras-chave: câncer cervical; gênero; Papanicolaou; saúde da mulher.

\begin{abstract}
Backgroud: Cervical cancer is a malignant neoplasm that affects thousands of women, and the Papanicolaou (Pap smear) test is considered the most effective prevention strategy. Objective: the purpose of this study is to understand the significance of the Pap test for a group of women undergoing cervical cancer prevention. Method: A qualitative study of ethnographic approach was conducted with nine women at reproductive age from the neighborhood of Jardim Keralux, located in the eastern district of the city of Sao Paulo. The choice of this location was due to the fact that it is a neighborhood whose population is considered vulnerable for access to the cervical cancer prevention network. Data from the interviews were assessed by content analysis. Results: The Papanicolaou test is permeated with meanings that range between the physical and moral planes of the lives of the women in this group. The Pap test makes disease visible in the female body, reinforcing belief in the possibilities of treatment and cure. It also enables visibility of an array of relationships in which women are involved, particularly regarding gender relations of the sociocultural context. Conclusion: The Papanicolaou test becomes part of the health care of this group of women, reinforcing their beliefs in the prevention of cervical cancer.
\end{abstract}

Keywords: cervical cancer; gender; Pap test; women's health.

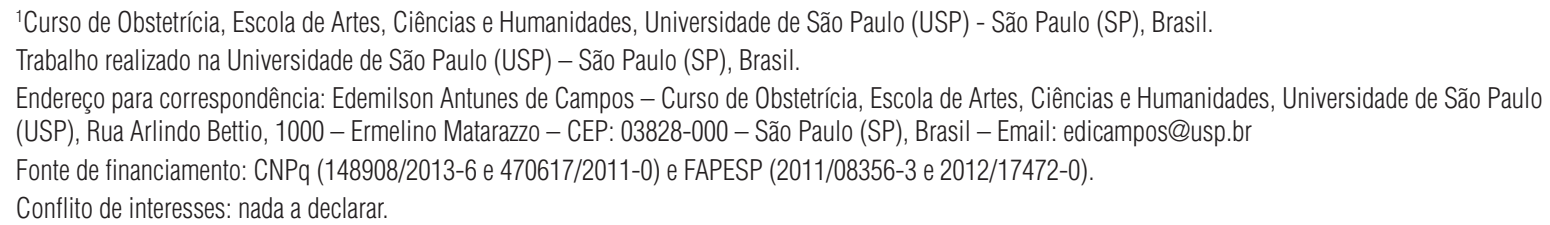




\section{INTRODUÇÃO}

O câncer cervical é uma neoplasia maligna que atinge milhares de mulheres em todo mundo, chamando a atenção da comunidade científica, das autoridades médicas e das governamentais. De acordo com estimativas mundiais para o ano de 2012, esse era o quarto tipo de câncer mais frequente entre as mulheres, sendo responsável pelo óbito de, aproximadamente, 265 mil mulheres em todo mundo, configurando-se em um importante problema de saúde pública ${ }^{1}$. Segundo dados do Instituto Nacional do Câncer (INCA), no Brasil, em 2016, havia um risco estimado de 15,85 casos novos de câncer cervical a cada 100 mil mulheres ${ }^{1}$.

Dada as altas prevalências do câncer cervical na população feminina, o Papanicolaou é considerado a mais efetiva estratégia de prevenção, devendo ser disponibilizado às mulheres com vida sexual ativa, na faixa etária de 25 a 64 anos, que é considerada à de maior incidência desse tipo de câncer ${ }^{2}$.

As pesquisas da área de Ciências Sociais e Saúde têm evidenciado o modo como os aspectos socioculturais influenciam na adesão das mulheres ao Papanicolaou. Exemplo disso são os trabalhos que enfatizam o conhecimento e a percepção das mulheres sobre o câncer, as suas formas de prevenção e as práticas de cuidado de $\mathrm{si}^{3}$; ou ainda, o estudo dos conhecimentos e das práticas médicas que chamaram atenção para o câncer de colo do útero, considerando-o um problema de saúde pública na sociedade brasileira, ao mesmo tempo que amplia os conhecimentos sobre a saúde da mulher ${ }^{4}$. Outra linha de pesquisa enfatiza a dimensão psicossocial na realização do Papanicolaou, na qual são apontadas as dificuldades encontradas pelas mulheres na realização do exame, tais como: o medo dos resultados, a falta de privacidade nos exames e de humanização no atendimento, a falta de sensibilização profissional para as rotinas de exames e a baixa prioridade do profissional no atendimento integral às mulheres, revelando sentimentos, como vergonha, medo $\mathrm{e}$ insegurança ${ }^{5}$.

Estudos destacam também como as complexas relações de gênero influenciam a prevenção do câncer cervical ${ }^{6}$. O conceito de gênero é social e historicamente construído, e define, de forma assimétrica, as relações entre homem e mulher, particularmente aquelas relativas ao corpo e à sexualidade ${ }^{7}$. Assim, a exposição da genitália feminina e a manipulação das zonas erógenas do corpo feminino pelo profissional de saúde podem gerar vergonha e constrangimento por se tratar de ações consideradas moralmente incorretas, levando as mulheres, muitas vezes, a não realizarem o Papanicolaou, principalmente quando o profissional é do gênero masculino.

Nessa linha, destaca-se também o estudo etnográfico de $\mathrm{Gregg}^{8}$ realizado em uma comunidade de mulheres que vivem na periferia de Recife, Pernambuco. Nele, enfatiza-se a maneira como a assimetria das relações de gênero constrange as mulheres em relação ao exercício da sexualidade, ao mesmo tempo que garante o apoio econômico dos homens. Com efeito, em meio a essa ambiguidade no exercício da sexualidade, marcada pelas relações de gênero, as mulheres aderem à prevenção do câncer cervical, enfatizando o discurso médico contra o comportamento sexual de risco, o que aumenta o controle sobre seu corpo e sua saúde.

É, portanto, seguindo a linha das pesquisas das Ciências Sociais e da Saúde que este artigo tem por objetivo compreender os sentidos do Papanicolaou para um grupo de mulheres moradoras da periferia da cidade de São Paulo.

\section{MÉTODO}

Foi realizada uma pesquisa qualitativa, com abordagem etnográfica e roteiro de entrevistas semiestruturadas, entre 2011 e 2013, com mulheres moradoras do Jardim Keralux, localizado no distrito de Ermelino Matarazzo, na zona leste da cidade de São Paulo. O projeto de pesquisa foi aprovado pelo Comitê de Ética em Pesquisa da Escola de Enfermagem da Universidade de São Paulo (CEP-EEUSP), processo número 1044/2011, e pelo Comitê de Ética em Pesquisa da Secretaria Municipal de Saúde de São Paulo (CEPSMS-SP), processo número 370/2011.

A escolha do local da pesquisa deveu-se, em primeiro lugar, ao fato de que é um bairro cuja população é considerada vulnerável para o acesso às redes de proteção à detecção precoce e ao tratamento do câncer de colo do útero.

O Jardim Keralux, ou "Kera”, como é conhecido por seus moradores, é um bairro popular que concentra uma população majoritariamente trabalhadora, a qual depende do próprio salário para sua reprodução social. A rotina dos moradores do Jardim Keralux começa cedo, às 6 horas da manhã, momento em que os moradores saem de suas casas e se dirigem ao trabalho utilizando a estação de trem ou o ônibus como meios de transporte.

A Unidade Básica de Saúde (UBS - Jardim Keralux) é o único acesso ao serviço de saúde daquela população, majoritariamente atendida pelo sistema público. É nesse local que as mulheres colhem o material para o exame citopatológico, o Papanicolaou.

A metodologia escolhida para realização desta pesquisa foi a etnografia, que tem como objetivo compreender cientificamente dada realidade sociocultural, a partir do ponto de vista "nativo", 10 . Trata-se de um método utilizado, tradicionalmente, pela Antropologia, com o objetivo de compreender o ponto de vista dos sujeitos da pesquisa, a partir dos significados que determinadas práticas sociais têm para aqueles que as vivenciam.

Nessa perspectiva, realizou-se um itinerário etnográfico no sentido estabelecido por Geertz" ${ }^{11}$, a saber, uma "descrição densa", na qual se busca compreender os significados que dão sentido aos atos cotidianos, tornando-os inteligíveis para aqueles que os praticam. Assim, procurou-se entender os sentidos do 
Papanicolaou para um grupo de mulheres que realiza a prevenção do câncer de colo uterino.

O encontro das mulheres que fizeram parte desta pesquisa se deu, em um primeiro momento, por meio da agente de saúde que atua no Jardim Keralux. Após a familiarização com o campo da pesquisa, o contato com as mulheres foi feito sem a necessidade dessa mediação. Elas foram selecionadas por meio da técnica denominada "bola de neve", na qual elas indicam outras para possível participação na pesquisa.

As entrevistas foram individuais e semiestruturadas e aconteceram entre os anos de 2012 e 2013. Todas concordaram em participar da pesquisa e assinaram o Termo de Consentimento Livre e Esclarecido (TCLE). Elas serão tratadas aqui por nomes fictícios, como forma de garantir o anonimato e o sigilo de suas informações.

Nesta pesquisa, foram entrevistadas nove mulheres, todas migrantes da região Nordeste do Brasil e moradoras de São Paulo há pelo menos 10 anos. Elas são mães de pelo menos um filho. Uma delas era dona de casa, enquanto as demais também trabalhavam em locais próximos ao Jardim Keralux, desempenhando funções que não exigiam uma formação técnica ou superior. Todas elas faziam o Papanicolaou periodicamente, pelo menos uma vez por ano.

As entrevistas foram gravadas, transcritas e analisadas com o objetivo de identificar, por meio da inferência, os núcleos de sentido e as significações sobre o Papanicolaou e suas implicações sobre a vida pessoal e familiar, visando a uma síntese interpretativa, permitindo compreender os sentidos que a prevenção do câncer de colo do útero tem para esse grupo de mulheres moradoras da periferia da cidade de São Paulo.

\section{RESULTADOS E DISCUSSÃO}

Embora, os Cadernos da Atenção Básica "Controle dos Cânceres do Colo do Útero e da Mama"12 estabeleçam que a mulher tenha o direito a uma assistência humanizada, com direito à informação sobre o exame citopatológico, e que as etapas do procedimento devem ser feitas de modo confortável, as mulheres entrevistadas têm uma interpretação própria da experiência do Papanicolaou: "Eu acho ruim fazer; eu acho ruim fazer o papa porque dói, dói bastante" (Vânia, entrevistada 02). Ou ainda:

Ela colhe o que tem que colher e pronto. O procedimento do Papanicolaou e pronto. Ela fala que tem que relaxar; ficar sossegada e não precisa se preocupar. Ela põe o bico lá e faz a culetagem normal (Sandra, entrevistada 07).

Durante a realização do exame, as mulheres tomam contato com o serviço de saúde e passam a vivenciar o processo de medicalização de seus $\operatorname{corpos}^{13}$. É nessa linha que se pode compreender o modo como as mulheres entrevistadas se referem à necessidade de realizar o Papanicolaou:
Eu faço a prevenção, porque as mulheres aparecem falando lá no Keralux que têm mioma, câncer, a gente escuta falar. Minha mãe mesmo também tinha mioma, mas tiraram por baixo e ela não precisou nem operar. Mas eu nunca tive mioma (Marcela, entrevistada 09).

Os contornos do processo saúde-doença são delineados pela apropriação do conhecimento médico, o qual passa a compor o campo semântico desse grupo de mulheres. Exemplo disso também está presente na narrativa de Yolanda, entrevistada 01, sobre a necessidade de a mulher fazer o Papanicolaou e a mamografia:

Não é só conversa, realmente ajuda. A mulher tem que fazer mesmo. Ela tem que se conscientizar, porque previne. Se a doença for detectada a tempo, tem mais chances de cura. Isso não é conversa, é a realidade mesmo. Eu acho que a mulher tem que fazer sim, uma vez por ano.

Nessa narrativa, os resultados do Papanicolaou ganham contornos de verdade, uma vez que eles podem revelar a doença e preveni-la. A medicalização do corpo da mulher vai, assim, consolidando-se e reafirmando a crença no saber médico e nas suas possibilidades de diagnóstico, tratamento e cura do câncer.

Uma análise das entrevistas realizadas também revela o modo como as mulheres vivenciam a experiência do Papanicolaou:

Ah, não é bom; é horrível fazer aquele exame, mas tem que fazer. Não machuca, não. Tem uns [profissionais de saúde] que machucam, outros não, depende das mãos, tem uns com mão pesada, outros com mão leve" (Mari, entrevistada 03).

Marcela, entrevistada 09, também faz a mesma avaliação sobre o modo como foi assistida durante a realização do exame:

[...] ela colocou aquele aparelho uma vez e não conseguiu. Ela colocou de novo e mandou eu relaxar. Doeu e saiu ardendo. No outro dia, minha barriga endureceu e ficou doendo [...] Ela tinha a mão muito pesada.

A dor é suportada, mesmo com o desconforto no momento da realização do exame. Isso remete à reflexão de Sarti ${ }^{14}$ sobre o modo como a dor é uma realidade simbólica que depende do lugar social do indivíduo, o que qualifica e determina a reação do outro diante da sua dor.

Mas, mesmo nesse contexto de dor e de desconforto em relação à prevenção, as mulheres também fazem uma avaliação dos profissionais de saúde e do modo como o exame foi realizado, demarcando a oposição entre os marcadores "leve" e "pesado" para se referir ao modo como o profissional realiza o Papanicolaou.

Com isso, evidencia-se uma qualificação do profissional de saúde a partir das percepções das mulheres, de maneira que ter a "mão leve" qualifica o profissional como atencioso, sensível e acolhedor, em oposição à "mão pesada", que faz dele desatencioso, insensível à dor e ao sofrimento. Trata-se, assim, de um modo de avaliação do cuidado, que aponta para a necessidade da 
relação e do vínculo entre os sujeitos - profissional e usuária - envolvidos na realização do exame.

A importância do acolhimento e de um cuidado humanizado fica evidente na narrativa de uma das mulheres, ao relatar a importância do vínculo com o profissional de saúde, quando da realização do Papanicolaou:

Eu sempre faço com a mesma enfermeira. Eu peço pra fazer com ela, porque ela é maravilhosa. Gosto muito dela, porque quando eu vou fazer, a gente começa a conversar. Ela deixa a gente relaxada. Ela começa a falar das filhas dela e eu começo a falar das minhas filhas, da minha família. Aí, quando ela termina, ela fala: "pronto, está pronto". Eu nem sinto. Eu sempre faço com ela. Lá, tem várias enfermeiras, mas eu prefiro fazer com ela, porque me sinto mais à vontade (Silvia, entrevistada 08).

A humanização em saúde sinaliza uma prática de cuidado centrada na relação e no vínculo entre profissional e usuário, no reconhecimento do "outro" e de suas especificidades pessoais e socioculturais, de maneira que se alie a competência técnica à ética das relações, para oferecer um cuidado respeitoso e de qualidade $^{15}$.

O vínculo entre o profissional e a usuária do sistema de saúde é fundamental, particularmente, no momento da realização do Papanicolaou. Assim, a valorização do vínculo com o profissional também indica um modo de avaliação do cuidado, em um sentido moral, que envolve a atenção oferecida durante o exame. Com efeito, a técnica do exame clínico adquire uma dimensão profunda e significativa, pois fazer o Papanicolaou com a mesma profissional torna o exame menos desconfortável, tanto do ponto de vista físico como moral.

É assim que o Papanicolaou é vivenciado, como uma prática de cuidado à saúde que articula as dimensões física e moral do corpo feminino, que dão sentido à prevenção do câncer de colo do útero.

\section{A PREVENCÃ̃o DO CÂNCER CERVICAL: EXPERIÊNCIA E SIGNIFICADO}

Quando falam sobre o Papanicolaou, as mulheres reconhecem a importância da prevenção do câncer cervical, ao mesmo tempo que dão um sentido à coleta de material para o exame citopatológico.

Elas acreditam que o Papanicolaou é importante para prevenir o câncer: "Tem que fazer o Papanicolaou para prevenir o câncer. Tem que se cuidar. A gente tem que se prevenir dessa doença. Não pode deixar de fazer o exame" (Mari, entrevistada 03). Ou mesmo: "Eu acho um exame muito importante, porque através dele a gente pode descobrir se tem algum problema e tem como cuidar" (Maísa, entrevistada 04). Ou ainda:

O Papanicolaou previne o câncer; quantas pessoas que, às vezes, já têm câncer e já estão em estado terminal e o médico não pode fazer nenhum tratamento. Então, a mulher tem que se cuidar e, com certeza, o Papanicolaou é muito importante" (Márcia, entrevistada 06).
Essas narrativas mostram que a importância do Papanicolaou está ligada à sua capacidade de "descobrir" se existe algum problema e cuidá-lo. A visibilidade da doença, que o exame possibilita, é um aspecto fundamental da lógica que orienta as mulheres e dá sentido à sua realização.

É isso o que nos diz Eliana sobre a importância dos exames clínicos, como o Papanicolaou:

Eu faço o Papanicolaou uma vez por ano. Eu fiz há seis meses. Eu fiz também o ultrassom das mamas, porque eu estava sentindo um nodolozinho, no período menstrual. Quando eu apalpava, sentia uma coisinha. Eu fiz para tirar a dúvida, mas graças a Deus, no exame não deu nada.

Os exames clínicos permitem "tirar a dúvida", produzindo um saber sobre algo que não se vê no interior do corpo. A visibilidade do exame produz uma verdade médica sobre o que é invisível aos olhos e que reforça a crença em sua eficácia. Essa capacidade do exame em tornar visível o interior do corpo é também um aspecto fundamental da "biomedicalização"16, ou seja, um ideal de transparência visual que amplia o alcance do processo de medicalização do corpo feminino.

Para as mulheres entrevistadas, o Papanicolaou não é concebido apenas como uma técnica, mas sim como um ritual terapêutico que permite a revelação da doença e sua prevenção. O que torna, para elas, a prevenção eficaz não é apenas sua técnica, mas a crença de que ele pode revelar a doença e preveni-la.

É isso que se pode interpretar da narrativa de Silvia, entrevistada 08 , em que narra como foi a primeira vez em que fez o Papanicolaou:

É que eu nunca tinha feito. Para começo de conversa, eu pensava como se fosse minha mãe, minha avó, eu pensava igual a elas: outro homem não podia ver meu corpo, só o meu marido. Só que quando eu ganhei minha filha, que eu fui ver. Quando eu fui para o hospital, eu fiquei nua lá, todo mundo me via. Então, aquilo mudou meu pensamento. Eu pensei: "poxa, eu estou aqui desse jeito, todo mundo está me vendo, e para eu fazer um Papanicolaou, que é bom pra mim, eu fico com vergonha, isso não!". Eu tenho que fazer o exame. Eles fizeram palestra comigo, com minhas irmãs, com as vizinhas. Eles conversaram muito com a gente. Eles falaram que era necessário, que era nossa obrigação. Então, a gente faz todo ano.

Silvia fez seu primeiro Papanicolaou quando chegou à São Paulo, grávida, e teve acesso ao sistema de saúde oficial e à sua rede de cuidados. É assim que ela foi apresentada a um modelo terapêutico para o diagnóstico do câncer de colo do útero. Tal como em um ritual de iniciação, ela vivenciou, no início, um sentimento moral de vergonha, de expor seu corpo diante do profissional de saúde. Um corpo que só poderia ser visto por seu marido, o que reafirma a lógica de gênero.

A vivência da gravidez no sistema de saúde oficial mudou seu pensamento e sua identidade de forma definitiva. Davis-Floyd ${ }^{17}$ enfatiza que a gravidez e o nascimento fazem parte de um ritual de passagem, que carrega a marca dos valores que a sociedade 
compartilha. Trata-se de um ritual cujo objetivo é o alinhamento das crenças e dos valores culturais de uma sociedade com o sistema de crenças do indivíduo.

Ora, Silvia vivenciou um processo ritual, que se iniciou no momento de sua gravidez, em que ela passou a fazer parte da rede de cuidados do sistema público de saúde. Essa vivência, que foi até o acompanhamento do filho nas consultas de puericultura, fez com que ela incorporasse o valor do cuidado médico.

Ao contrário de sua mãe, que tinha vergonha de ficar nua e expor sua intimidade para o profissional de saúde, Silvia reconheceu a importância do Papanicolaou para o cuidado de sua saúde.

As palestras e as conversas com os profissionais de saúde ratificam e legitimam a importância da prevenção para o cuidado da saúde, que deixa de ser apenas uma técnica para tornar-se uma "necessidade-obrigação", que deve ser feita todo ano: "Eu sempre gosto que o médico me examine para saber se está tudo bem com minha saúde" (Silvia, entrevistada 08).

Ir ao médico e fazer o Papanicolaou faz parte do ritual terapêutico das mulheres que, assim, confirmam a crença de que se previnem do câncer de colo do útero, ao mesmo tempo que cuidam de sua saúde.

\section{CUIDADO À SAÚDE, GÊNERO E O PAPANICOLAOU}

A gravidez é o momento em que muitas mulheres acessam o serviço de saúde e fazem o Papanicolaou. É isso que afirma Mari, entrevistada 03: "Eu fiz o primeiro exame há muito anos, quando eu tive minha primeira filha, que está com 27 anos". Isso fica ainda mais evidente na narrativa de Eliana, entrevistada 05, na qual expõe sua experiência de contato com o sistema de saúde durante a gravidez:

Antes de eu ficar grávida, era bem difícil eu fazer o Papanicolaou, eu só fazia a cada cinco anos. Quando Você fica grávida, começa a fazer o pré-natal e tem aquele acompanhamento todo mês. Eu não estava acostumada. Depois disso, eu comecei a levar mais a sério e me cuidei mais. Porque eu nunca tinha feitos esses exames. Quando se está grávida temos que fazer todo quanto é tipo de exame: HIV, tudo. Eu acho muito legal e antes eu nunca tinha feito. Agora, eu faço o Papanicolaou todo ano.

Elas passam a vivenciar a rotina das consultas do pré-natal, do parto e dos cuidados do pós-parto, o que as colocam dentro da malha de cuidados oferecida pelo sistema de saúde e sua lógica médica fisicalista, a qual reafirma a crença nos valores do modelo médico de atenção à saúde.

É certo que a gravidez, além de colocar a mulher diante da rotina dos exames clínicos, também opera uma mudança de status na vida da mulher que vivencia a experiência de tornar-se mãe. Yolanda, entrevistada 01, também deixa claro o modo como a maternidade mudou sua vida:

Eu não levava a vida muito a sério, e depois que minha filha veio, realmente, eu mudei muitas coisas; eu aprendi a ser uma pessoa responsável em todos os sentidos. Eu era bem irresponsável, no sentido de que não estava nem aí. Em minha cidade, eu só queria saber de balada, de beber. Então, geralmente, quando você está nessa fase de curtição, você não pensa na saúde. Eu vim a pensar depois que minha filha nasceu. Hoje, já não faço mais isso. Porque depois da minha filha nasceu, eu tive que focar. Como eu sou mãe solteira, eu tive que focar só na minha filha.

Essa narrativa expõe o modo como a mulher-mãe passa a ser alvo de prescrições socialmente definidas, como parte de um processo ritual, fundamental para a construção do valor da maternidade e, por essa via, para responsabilizar-se pelo cuidado de sua saúde e de sua filha.

A literatura socioantropológica tem enfatizado o modo como a maternidade opera enquanto um importante valor moral para as mulheres das camadas populares. É seguindo essa linha que Sarti ${ }^{18}$ aponta que autoridade da mulher vincula-se à valorização da mãe, em um universo simbólico em que a maternidade a faz mulher, tornando-a reconhecida como tal.

As práticas de cuidados à saúde, tal como a realização do Papanicolaou, remetem aos códigos sociais e culturais vivenciados no contexto no qual as mulheres estão inseridas. $\mathrm{O}$ valor moral da maternidade, ligado à imagem da "boa mãe", reforça a ideia de que a mulher deve cuidar de si, na medida em que ela é responsável pelo cuidado de sua saúde e da de seu filho.

A mulher desempenha na família um papel diferencial e complementar em relação ao homem, de maneira que é justamente de sua condição de "dona de casa" ou de "chefe da casa" que se irradiam as marcas fundamentais de sua autoridade no espaço da casa ${ }^{18}$.

Essa responsabilidade pelo cuidado de sua saúde e da de seus familiares também se liga à hierarquia de gênero, tal como deixa entrever Sandra, entrevistada 07, na relação com seu marido, que nunca fez o exame de próstata, e com seus filhos:

Meu marido não se cuida, eu insisto para ele ir ao médico, mas
eu acho o homem esquisito. Eu falo para meus filhos que quando
chegar aos 30 anos, é importante procurar um urologista para
cuidar desse negocio aí. Eles dão risadas e são mais abertos.
Acho que é o jeito que eu criei meus filhos. As minhas filhas
procuram o médico e explicam o que estão sentindo, se está
com escorrimento. Elas vão ao médico. Se elas reclamam para
mim, eu falo: "procura um médico", pois não pode ficar assim;
é perigoso ter um câncer de útero.

O Papanicolaou permite visualizar a lógica de gênero presente no contexto familiar, a qual define, assimetricamente, as relações entre o homem e a mulher. Sandra busca mostrar ao seu marido e aos seus filhos a importância do cuidado da saúde.

O marido de Sandra não se cuida e não vai ao médico, o que remete às representações da saúde ligadas à força física, de maneira que é considerado saudável o homem com capacidade de trabalhar, mas que acaba, muitas vezes, por afastá-lo do serviço de saúde oficial ${ }^{19}$. 
O câncer cervical é uma doença de gênero ${ }^{7}$ que exige que a mulher cuide de sua saúde por meio do Papanicolaou. O câncer é uma doença do indivíduo, mas não pode ser pensado senão nas relações sociais em que ele está inserido ${ }^{20}$. Se o câncer cervical é uma doença do gênero feminino, sua prevenção por meio do Papanicolaou é uma necessidade para a saúde da mulher.

\section{CONSIDERAÇÕES FINAIS}

O câncer cervical é um importante problema de saúde pública e, apesar de o Papanicolaou permitir sua prevenção, seu diagnóstico e seu tratamento, apresenta alta taxa de mortalidade na sociedade brasileira.

Neste artigo, buscou-se compreender os aspectos socioculturais que operam na prevenção do câncer cervical a partir dos sentidos que o Papanicolaou tem para um grupo de mulheres moradoras da periferia da cidade de São Paulo.

Para elas, realizar o Papanicolaou é fundamental para a prevenção do câncer, sobretudo por sua capacidade de tornar visível a doença e, assim, reforçar a sua crença no saber médico e nas possibilidades de diagnosticar, tratar e curar o câncer. Com isso, reforça-se a biomedicalização, de maneira que a medicina moderna, com seu arsenal técnico-científico, tais como exames de diagnósticos, laboratoriais, de imagem etc., aumenta a interferência no dia a dia da população por meio de normas de condutas e comportamentos em relação à sua saúde.

Com efeito, se o Papanicolaou permite visualizar precocemente a doença no interior do corpo feminino, ele também torna visível o leque de relações nas quais as mulheres estão envolvidas, particularmente as relações de gênero, que marcam os valores morais próprios do contexto sociocultural no qual elas vivem com sua família.

É assim que esse grupo de mulheres moradoras da periferia da cidade de São Paulo cuida de sua saúde e a de seus familiares, de maneira que o Papanicolaou passa a fazer parte de suas vidas, reafirmando a crença na prevenção do câncer cervical.

\section{REFERÊNCIAS}

1. Brasil. Ministério da Saúde. Instituto Nacional de Câncer José Alencar. Coordenação de Prevenção e Vigilância. Estimativas 2016: incidência de câncer no Brasil. Rio de Janeiro: INCA; 2015.

2. Brasil. Ministério da Saúde. Instituto Nacional de Câncer José Alencar. Coordenação Geral de Ações Estratégicas. Divisão de Apoio à Rede de Atenção Oncológica. Diretrizes brasileiras para o rastreamento do câncer do colo do útero. Rio de Janeiro: INCA; 2011.

3. Urrutia MT, Poupin L. Women with cervical cancer: perceptions about the Papanicolaou test. Aquichan. 2015;15(4):499-507. http://dx.doi.org/10.5294/ aqui.2015.15.4.5

4. Teixeira LA. Dos gabinetes de ginecologia às campanhas de rastreamento: a trajetória da prevenção ao câncer de colo do útero no Brasil. Hist Cienc Saude Manguinhos. 2015;22(1):221-39. http://dx.doi.org/10.1590/S010459702015000100013. PMid:25742108.

5. Cruz LMB, Loureiro RPA. Comunicação na abordagem preventiva do câncer de colo do útero: importância das influências histórico-culturais e da sexualidade feminina na adesão as campanhas. Saude Soc. 2008;17(2):12031. http://dx.doi.org/10.1590/S0104-12902008000200012.

6. Löwy I. Le genre du cancer. Femmes, Genre, Histoire. 2013;37:65-83. http:// dx.doi.org/10.4000/clio.10986.

7. Heilborn ML. Articulando gênero, sexo e sexualidade: diferença na saúde. In: Goldenberg P, Marsiglia RMG, Gomes MHA, editores. O clássico e o novo: tendências, objetos e abordagens em ciências sociais e saúde. Rio de Janeiro: Editora Fiocruz; 2003. p. 197-208.

8. Gregg J. Virtually virgins: sexual strategies and cervical cancer in Recife, Brazil. Stanford: Stanford University Press. 2003.

9. Nakamura E. O lugar do método etnográfico em pesquisa sobre saúde, doença e cuidado. In: Nakamura E, Martin D, Santos JFQ, editores. Antropologia para enfermagem. São Paulo: Manole; 2009. p. 15-34.

10. Victora C, Knauth DR, Hassen MNA. Pesquisa qualitativa em saúde: uma introdução ao tema. Porto Alegre: Tomo Editorial; 2000
11. Geertz C. A interpretação das culturas. Rio de Janeiro: Guanabara; 1989.

12. Brasil. Ministério da Saúde. Secretaria de Atenção à Saúde. Departamento de Atenção Básica. Controle dos cânceres do colo do útero e da mama. 2. ed. Brasília: Ministério da Saúde; 2013.

13. Conrad P. The medicalization of society: on the transformation of human conditions into treatable disorders. Baltimore: Johns Hopkins University Press; 2007.

14. Sarti CA. A dor, o indivíduo e a cultura. Saude Soc. 2001;10(1):3-13. http:// dx.doi.org/10.1590/S0104-12902001000100002.

15. Rios IC. Humanização: a essência da ação técnica e ética nas práticas de saúde. Rev Bras Educ Med. 2009;33(2):253-61. http://dx.doi.org/10.1590/ S0100-55022009000200013.

16. Clarke A. From the rise of medicine to biomedicalization: U.S. healthscapes and iconography, circa 1890-present. In: Clarke AE, Mamo L, Fosket JR, Fishman JR, Shim JK. Biomedicalization: technoscience, health and illness in the US. Durham: Duke University Press; 2010.

17. Davis-Floyd R. Birth as an American rite of passage. 2nd ed. Berkeley: University of California Press; 2003

18. Sarti CA. A família como espelho: um estudo sobre a moral dos pobres. 3. ed. São Paulo: Cortez Editora; 2005.

19. Gomes R, Nascimento EF, Araujo FC. Por que os homens buscam menos os serviços de saúde do que as mulheres? As explicações de homens com baixa escolaridade e homens com ensino superior. Cad Saude Publica. 2007;23(3):565-74. http://dx.doi.org/10.1590/S0102-311X2007000300015. PMid:17334571.

20. Herzlich C, Pierret J. Malades d'hier, malades d'aujourd'hui: de la mort collective au devoir de guérison. Paris: Éditions Payot; 1991.

Recebido em: Out. 07, 2016 Aprovado em: Maio 21, 2018 